\title{
A noção de eficácia nas consultas mediúnicas da umbanda
}

\section{Notion of effectiveness in Umbanda mediumistic consultations}

\author{
Luciana Macedo Ferreira Silva* \\ Fabio Scorsolini-Comin**
}

\begin{abstract}
Resumo: O objetivo do presente estudo é problematizar a noção de eficácia a partir das consultas mediúnicas realizadas no contexto da umbanda com consulentes que apresentam queixas de saúde. Participaram 20 consulentes atendidos em dois centros de umbanda da cidade de Uberaba, Minas Gerais, Brasil. As entrevistas foram submetidas à análise temática reflexiva. Emergiram quatro temas principais: 1) Conhecimento dos benefícios do tratamento por meio de terceiros; 2) Solicitação e execução dos pedidos realizados pelas entidades; 3) Simbolismos catalizadores da eficácia; 4) A eficácia do trabalho mediúnico mediante o comportamento dos consulentes. A umbanda, ao ser situada como equipamento popular de saúde, permite a emergência de uma noção de eficácia que ultrapassa o modelo biomédico, em um paradigma de integralidade e de humanização.
\end{abstract}

Palavras-chave: Religiosidade. Espiritualidade. Etnopsicologia. Umbanda.

Abstract: The present study aims to problematize the notion of effectiveness from mediumistic consultations held in Umbanda with consultants who present health complaints. Participated in 20 consultants attended at two Umbanda centers in the city of Uberaba, State of Minas Gerais, Brazil. The interviews were submitted to reflexive thematic analysis. Four main themes emerged: 1) Knowledge of the benefits of treatment through third parties; 2) Request and execution of requests made by the entities; 3) Symbolisms that catalyze effectiveness; 4) The effectiveness of mediumistic work through the behavior of the consultants. When it is located as a piece of popular health equipment, Umbanda allows the emergence of a notion of effectiveness beyond the biomedical model, in a model of integrality and humanization.

Keywords: Religiosity. Spirituality. Ethnopsychology. Umbanda.

\section{Introduçáo}

A religiosidade está intimamente ligada a elementos doutrinários, ritualísticos e éticos de cada religiáo, assegurando diretivas para as condutas humanas associadas a uma complexidade de interesses morais e motivacionais que podem evitar comportamentos considerados autodestrutivos para a saúde (Zerbetto, Gonçalves, Santile, Galera, Acorinte, Giovannetti, 2017). Já a espiritualidade está diretamente associada ao sagrado, vinculando-se à crença em um poder superior, almejando entendimento

\footnotetext{
* $\quad$ Mestra em Psicologia (UFTM, Uberaba-MG). ORCID: 0000-0003-4617-8421 - contato: macedo. luciana@outlook.com

** Professor do Departamento de Enfermagem Psiquiátrica e Ciências Humanas da USP (São Paulo-SP). Doutor em Psicologia (USP). ORCID: 0000-0001-6281-3371 - contato: fabioscorsolini@gmail.com
} 
e significado da vida. Em que pesem as especificidades de cada um desses termos, religiosidade e espiritualidade, o termo combinado religiosidade/espiritualidade (R/E) tem sido empregado na literatura do campo da saúde como forma de compreender os desfechos dessa dimensão nos contextos de cuidado (Cunha, Scorsolini-Comin, 2019; Silva, Scorsolini-Comin, 2020).

A literatura tem investigado em que medida a R/E pode atuar na promoçáo do conforto emocional em situaçóes críticas, haja vista que sujeitos que apresentam envolvimento em atividades de cunho religioso-espiritual demonstram mais recursos de enfrentamento, bem como a perspectiva de se maximizar pensamentos otimistas para impasses pessoais e que proporcionam alívio e conforto aos seus praticantes e adeptos (Amaral, Menezes, Silva, Oliveira, 2016). Nesse sentido, podemos ressaltar que a R/E se caracteriza como um instrumento que transcende a vida humana e que viabiliza o auxílio, conforto e fortalecimento nas questóes de saúde física e mental por meio das crenças e valores pré-estabelecidos no momento das intervençôes espirituais, contribuindo, assim, para a qualidade de vida dos sujeitos (Amaral et al., 2016).

Nesse domínio, podemos abordar as diversas religiôes que possuem como objetivo a promoção do bem-estar de seus adeptos. No que tange especificamente aos processos de saúde e doença, e também de cura, a umbanda é uma religiáo que ganha particular interesse no cenário nacional não apenas por ser uma religiáo brasileira, mas por reunir, em seu panteão, elementos que remetem ao kardecismo, ao catolicismo e ao candomblé africano (Negrăo, 1993; Concone, 2014). Sendo porosa a essas influências, a umbanda representa também o modo como diferentes religióes encontram no Brasil uma forma de conviver, de influenciarem e de serem influenciadas, representando sociabilidades que possuem como importante marcador os processos de saúde e doença.

Um dos elementos rituais mais expressivos da umbanda é a consulta mediúnica, espaço no qual um médium, a partir da incorporação de uma entidade espiritual, atende a um fiel em busca de ajuda. Nessas consultas busca-se solucionar toda sorte de problemáticas, como questôes amorosas, financeiras, familiares e, principalmente, demandas relativas à saúde (Negráo, 1993; Scorsolini-Comin, 2014). A consulta também representa um momento ritual importante no qual o consulente entra em contato direto com uma divindade por meio de um médium em transe mediúnico, permitindo um diálogo entre o mundo material e o mundo espiritual, entre uma pessoa em busca de ajuda e orientação e o divino.

Para Montero (1994), a umbanda compreende o adoecimento dentro da noçáo de desordem, de modo que rituais como consultas, passes, banhos e defumaçóes têm por objetivo simbólico restabelecerem a saúde e o bom funcionamento do organismo. A umbanda foi e tem sido alvo de diferentes perseguiçóes relacionadas a elementos como a intolerância religiosa, o racismo e também o ceticismo em relação aos seus rituais (Delmonte, Farias, 2017), o que também não pode ser apartado do fato de se tratar de uma religião de matriz africana em um contexto opressor em relação a estas tradições históricas.

Desde o seu início, a umbanda tem representado um conjunto religioso simbólico popular na vida das pessoas que buscam respostas que a ciência e a própria inteligibilidade humana não são capazes de conceder. Diante da complexidade envolvida nos 
processos de saúde e doença, e na execução das práticas ritualísticas, temos que é de fundamental importância entender o significado que o sujeito dá ao tratamento realizado, bem como as orientaçóes fornecidas pelos guias espirituais, estabelecendo-se formas de se conceber o conhecimento de saúde e doença, considerando a subjetividade, as vivências dos indivíduos, bem como a noção de eficácia das práticas mágicas perante o cumprimento dessas orientaçóes.

$\mathrm{Na}$ antropologia, a discussão sobre a eficácia simbólica tem se baseado classicamente nas consideraçóes de Lévi-Strauss (1975), publicadas originalmente em 1949. No entanto, tais consideraçóes também têm sido revisitadas na contemporaneidade tomando por base distintos contextos de cuidado em saúde, como os da medicina tradicional em Moçambique (José Fialho, 2003) e de povos indígenas do Gran Chaco (Renshaw, 2006), apenas para citar dois exemplos, mas também em função de diversos atravessamentos que questionam, entre outros, o modo como a psicanálise também foi cotejada no pensamento de Lévi-Strauss, devendo ser esta abordagem revisitada na contemporaneidade e tendo como marcadores os desafios impostos pelo mercado do cuidado, o que envolve diretamente os equipamentos formais de saúde e suas lógicas. $\mathrm{Na}$ contemporaneidade, esses ordenadores da significação pretensamente universais presentes nos rituais mágicos têm sido suspensos, primando por uma discussão mais dinâmica e que náo necessariamente responde de modo definitivo à questão da eficácia (Maluf, 2005; Tavares \& Bassi, 2012). Alguns desses endereçamentos parecem encontrar no contexto da umbanda um campo de discussão oportuno, como discutiremos a seguir.

No contexto da umbanda, a eficácia mágica está relacionada ao simbolismo, representado pela confiabilidade no médium, nas orientaçóes espirituais que permitem a transformação da realidade e na busca incessante pela cura. Tais modificaçôes acontecem, sobretudo, quanto há grande influência dos aspectos espirituais na consciência e na crença dos indivíduos, que recorrem à umbanda como meio para lidar com o adoecimento, apresentando certa dependência das soluçôes desenvolvidas pelo pensamento mágico, em detrimento do pensamento racional, pautado nos conhecimentos e vivências particulares (Montero, 1994). Essas significaçōes e esses simbolismos acerca da eficácia emergem de modo integrado e como forma de produzir respostas coletivas que pensam o cuidado também como recurso para o fortalecimento de laços sociais, integraçáo social e controle da incerteza, para além de uma resposta unívoca acerca da cura ou do pleno restabelecimento da saúde de um ponto de vista exclusivamente biomédico (José Fialho, 2003).

Diante desses aspectos, discorre-se que as crenças religiosas se fazem presentes de modo intenso no cotidiano dos sujeitos, e este seria um dos fatores que fundamentam a busca pelo entendimento dos benefícios dessa religião sobre as queixas de saúde (Silva, Scorsolini-Comin, 2020). Este estudo parte da necessidade de compreender as motivaçôes dos consulentes para início e tratamento pela assistência espiritual, bem como o modo que estes consulentes avaliam e interpretam o tratamento realizado no terreiro de umbanda (Abdala, Kimura, Duarte, Lebrão, Santos, 2015). Embora a literatura aqui recuperada seja uníssona em reconhecer a importância que os adeptos da umbanda atribuem às orientaçóes recebidas durantes as consultas mediúnicas, há que se compreender de que modo tais consulentes produzem inteligibilidades nativas acerca da 
eficácia de tais práticas espirituais, o que provavelmente esteja relacionado com o retorno constante a esses rituais como forma de solução de problemas relacionados à saúde.

Tal necessidade foi direcionada por meio da etnopsicologia (Leal de Barros, Bairrão, 2010; Scorsolini-Comin, 2014). Esse método iniciou-se sob a influência da escola americana de antropologia cultural e da personalidade, baseando-se nas práticas de observação, norteadas pelas questóes culturais e pelo comportamento humano (Lutz, 1985). De modo geral, a etnopsicologia aborda detalhadamente as experiências humanas diante de temáticas complexas como, por exemplo, culturas, valores e crenças religiosas. Nessas experiências, busca-se compreender processos de conflitos e emoçóes interpessoais, perpetuando-se saberes, tanto do pesquisador quanto do pesquisado e suas comunidades (Laplantine, 1986; Leal de Barros, Bairráo, 2010; Macedo, 2015; Scorsolini-Comin, 2014). A partir do panorama exposto, o objetivo do presente estudo é problematizar a noção de eficácia a partir das consultas mediúnicas realizadas no contexto da umbanda com consulentes que apresentam queixas de saúde.

\section{Método}

Estudo exploratório, qualitativo e de corte transversal, amparado na etnopsicologia. $\mathrm{Na}$ execução do estudo foram considerados os itens presentes no protocolo COREQ para pesquisas qualitativas.

Participaram 20 consulentes atendidos em dois centros de umbanda da cidade de Uberaba, Estado de Minas Gerais, Brasil. Um deles foi fundado em 1993 e o outro em 2010. A idade dos respondentes variou de 21 a 32 anos. Inicialmente, a pesquisadora realizou contato prévio com os dirigentes dos centros, solicitando a autorização dos mesmo para a realização da pesquisa, que envolvia a frequência semanal da pesquisadora nesses espaços, bem como o contato da mesma com os consulentes nos dias de atendimentos abertos ao público. Em um desses centros, os trabalhos de assistência espiritual acontecem às terças-feiras, atendendo em média 30 consulentes por encontro. $\mathrm{O}$ outro centro recebe em torno de 60 consulentes a cada encontro, realizado sempre às quartas-feiras. Em ambos os locais, a cada trabalho cultuam-se entidades diferentes, como caboclos, erês, pretos-velhos, baianos, marinheiros, boiadeiros e ciganos. Esses espíritos são incorporados pelos médiuns que fazem parte dos centros. Para a realização deste estudo, foi utilizado um roteiro de entrevista elaborado pelos próprios pesquisadores contendo questóes relacionadas às características sociodemográficas, à história de vida do sujeito, o significado da religião, o desenvolvimento do processo saúde/doença, o processo de escolha pelo tratamento espiritual e o tratamento em curso. A pesquisadora construiu um diário de campo abrangendo informaçóes quanto às giras (cerimônias), os atendimentos realizados, o recrutamento dos participantes, observaçóes pessoais e elementos considerados pertinentes à pesquisa, bem como o número de consulentes por trabalho espiritual desenvolvido, número de médiuns em atendimento, aspectos relacionados ao ambiente e ao trabalho mediúnico, com especial atenção aos sentimentos produzidos e pesquisadora durante a coleta de dados. 
Conforme orientaçóes da pesquisa etnopsicológica, este estudo teve início com o desenvolvimento do trabalho de campo (Silva, Scorsolini-Comin, 2020). A pesquisadora se dirigiu às comunidades religiosas em tela em dias de assistência ao público para conhecer o funcionamento da instituição e os potenciais participantes, almejando familiarizar-se com as instituições, suas formas de organização e seus frequentadores. Após indicaçôes dos potenciais participantes por parte dos dirigentes, ou seja, de pessoas que estavam em tratamento por alguma queixa de saúde, a pesquisadora realizou sua apresentaçáo aos consulentes, destacando o objetivo deste estudo e os termos para a participação. A indicação dos dirigentes náo teve o objetivo de selecionar os potenciais participantes de modo exclusivo, mas sim de permitir um acesso mais rápido aos voluntários que atendessem ao critério fundamental para a pesquisa, que era o engajamento em tratamentos espirituais por queixas de adoecimento. Assim, os dirigentes informavam à pesquisadora, a cada gira, quais pessoas estavam frequentando o terreiro por conta desses aspectos, em uma espécie de recrutamento. A pesquisadora, então, entrava em contato com todos os potenciais participantes, explicando as condiçóes do estudo e considerando se as mesmas atendiam ou não aos critérios de inclusão, bem como verificando o consentimento com a participaçáo ou não. Desse modo, a seleção era feita exclusivamente pela pesquisadora em campo. Alguns desses participantes também foram recrutados pela própria pesquisadora em campo, por meio da frequência às giras, por exemplo, estabelecendo contatos com os frequentadores antes do início dos trabalhos, em uma espécie de "sala de espera", tomando como metáfora os modelos formais de atendimentos em saúde.

A coleta de dados se deu de modo individual com os consulentes selecionados segundo critérios de inclusão pré-estabelecidos para esta pesquisa. Posteriormente à anuência dos voluntários, agendou-se as entrevistas conforme disponibilidade dos mesmos. A pesquisadora foi a responsável por realizar as entrevistas, considerando aspectos como os locais de fácil acesso e que garantissem a privacidade do entrevistado, sendo estas realizadas nas residências dos participantes ou na própria instituição, em sala reservada e disponibilizada pelos dirigentes. $\mathrm{O}$ termo de esclarecimento era apresentado aos entrevistados e, posteriormente à leitura e anuência do mesmo, o entrevistado assinava o termo de consentimento livre e esclarecido. As entrevistas foram realizadas face a face, individualmente, sendo audiogravadas mediante autorização do entrevistado e posteriormente transcritas na íntegra e literalmente para a composição do analítico. A coleta de dados foi encerrada quando se atingiu o critério de saturaçáo em função da repetiçáo de temas e sentidos por parte dos participantes da pesquisa. O período de coleta das entrevistas foi de seis meses, mas a frequência da pesquisadora à comunidade foi de um ano, considerando todo o período de observações iniciais, apresentação do projeto aos dirigentes e à comunidade e de coleta. Para a análise do presente estudo foram priorizadas as entrevistas como fonte de evidência, a fim de permitir o acesso aos relatos dos frequentadores e a emergência de sentidos sobre a eficácia produzidos por eles nesse contexto de cuidado. O diário de campo foi empregado para acessar os dados de caracterizaçáo da amostra, do campo empírico e para a descriçáo do percurso de produção e interpretaçáo dos dados.

$\mathrm{O}$ analítico foi submetido à análise temática reflexiva proposta por Braun e Clarke (2019), permitindo a construção de temas Este procedimento foi realizado em investigação 
anterior (Silva, Scorsolini-Comin, 2020). Para a interpretação do e dos temas produzidos, dialogou-se com a literatura científica da área de R/E e também com a etnopsicologia, sobretudo com estudos desenvolvidos no cenário da umbanda no Brasil e tomando por referência o encontro entre autores clássicos e contemporâneos desse contexto (Augras, 2012; Bairrão, 2012; Laplantine, 1986; Macedo, 2015; Montero, 1994; Scorsolini-Comin, 2014).

Este estudo foi aprovado pelo Comitê de Ética em Pesquisa da Universidade Federal do Triângulo Mineiro (CAAE no 93744318.1.0000.5154).

\section{Resultados e discussáo}

Quanto ao reconhecimento da religiáo mediante os benefícios de saúde alcançados pelo envolvimento nos atendimentos mediúnicos, os 20 consulentes relataram melhora nos quadros de saúde, tanto em aspectos físicos, como mentais, destacando-se, em todos os casos, a melhora dos sintomas em comparaçáo com o início do tratamento espiritual. Após a análise temática, emergiram quatro temas principais a partir dos sentidos de saúde-doença relatados pelos consulentes. Em um primeiro tema, intitulado "Conhecimento dos benefícios do tratamento por meio de terceiros", destaca-se que a busca pelo tratamento espiritual partiu de sua recomendaçáo por parte de outros consulentes que frequentavam $o$ mesmo terreiro e relatavam desfechos positivos nesse domínio. Um segundo tema, intitulado "Solicitação e execução dos pedidos realizados pelas entidades", abarca de que modo os consulentes seguem ou não as orientaçóes e recomendaçóes recebidas pelos espíritos durante as consultas mediúnicas. Outros dois temas também foram produzidos, a saber: "Simbolismos catalizadores da eficácia" e "A eficácia do trabalho mediúnico mediante o comportamento dos consulentes". Os argumentos em cada eixo temático foram demonstrados com falas representativas do conteúdo exposto. Para preservar a identidade dos participantes, seus nomes foram substituídos por $\mathrm{P}$ (participantes), acrescidos do número da entrevista. A seguir, esses temas serão discutidos.

\section{Conhecimento dos beneficios do tratamento por meio de terceiros}

Considerando-se a importância e o significado do contexto religioso no cotidiano dos sujeitos, podemos destacar que a dimensão religiosa e espiritual amplia sua credibilidade e conhecimento mediante diálogo entre consulentes que obtiveram benefícios frente ao tratamento espiritual. Nesta categoria podemos identificar que muitos dos consulentes recorrem à umbanda quando percebem o êxito do tratamento com outros consulentes, e que as realizaçóes alcançadas por terceiros passam a ser um estímulo e uma motivação para a procura das práticas religiosas, como pode ser observado nas falas a seguir.

Conheço outras pessoas que se tratam aqui, cada um com um problema diferente. Diziam que já tinham buscado todas as alternativas, físicas, terrestres, e não tinha achado solução, a maioria das pessoas busca o que ela consegue ver, até ela cair a ficha de que o problema não é físico, é espiritual (P3). 


\begin{abstract}
Conheço algumas pessoas, até uma que eu conheci lá dentro e falou, oh você continua vindo aqui, que eu tinha um problema semelhante ao seu, e consegui melhorar, então continua vindo. Então são pessoas que estavam nesse nível e que foi curado lá dentro (P4).

Conheço muitos que estão lá foi por motivo de doença, de depressão e por perdas e se curam (P8).
\end{abstract}

Por meio dessas falas, podemos notar que muitas vezes o tratamento espiritual ganha ênfase a partir da disseminação de informaçóes e resultados obtidos por intermédio de terceiros. $\mathrm{O}$ resultado benéfico alcançado pelo outro se torna um aspecto motivacional para a busca pelo tratamento espiritual. Diante disso, nota-se um crescimento quanto à adesão às diversas religióes e formas de rituais, dando destaque para religióes que apresentam acentuadamente um caráter mágico, como a umbanda (Montero, 1994).

Embora o termo magia seja frequentemente evocado no contexto umbandista, Augras (2012) nos adverte que o mesmo não pode ser empregado em oposiçáo ao conceito de religião ou de religiosidade, de modo que em todas as religióes há elementos considerados mágicos, o que traz à magia não uma acepçáo de algo subversivo ou tangencial, mas essencialmente cravado no panteão de todos os códigos religiosos. Esse movimento pode ser observado na umbanda, em que a magia faz parte de todos os rituais, não sendo uma categoria à parte, mas algo integrado à religião.

Ainda segundo Augras (2012), a noção de eficácia está diretamente associada à de magia: "Magia é ação concreta e visa à pura eficácia" (p. 14). Dessa monta, deve-se destacar que a umbanda trabalha com os elementos mágicos de modo concreto, ou seja, que esses elementos contribuem para a construção de um sentido de eficácia, de algo que pode estar mais próximo do sujeito e que, apesar de náo poder ser controlado por ele, pode ser observado e corporificado pelo mesmo. Esse sentido é recuperado pelos consulentes, que náo visam a construir necessariamente uma inteligibilidade capaz de explicar a eficácia, mas de experienciá-la junto com a magia, no acontecer dos rituais e dos tratamentos.

Os benefícios do tratamento vão sendo disseminados mediante diálogos que provocam a curiosidade, a credibilidade, bem como a expectativa de cura para enfermidades. No entanto, como trazido de modo uníssono pelos consulentes entrevistados, é necessário que o frequentador acredite em algo superior, que se sustente na fé, para que se obtenham os resultados descritos como positivos.

A credibilidade dada aos tratamentos realizados encaminha-se para três aspectos complementares que favorecem a obtenção dos benefícios espirituais, como a própria crença do feiticeiro na eficácia de suas técnicas, a crença do doente no poder do próprio feiticeiro e, por fim, a confiança e as exigências da opiniáo coletiva, que em muitas situaçóes atua como influenciadora na busca pelo tratamento espiritual. Esta influência vem associada à noção de eficácia simbólica no momento em que o sujeito valida o poder do terreiro e do trabalho realizado e este é considerado como eficiente, havendo um reconhecimento social comunitário (Lévi-Strauss, 1975). Esse pensamento amplamente conhecido na obra de Lévi-Strauss pode ser corporificado no estudo em tela, haja vista que os adeptos reconhecem o poder dessa comunicação coletiva acerca da eficácia, mas também asseveram que a mesma deve ser acompanhada pela crença de 
quem busca o atendimento. Assim, é na confluência desses elementos que a noção de eficácia se sustenta no contexto das consultas mediúnicas da umbanda.

Também há que se assinalar que essa eficácia simbólica emerge de modo integrado às medicinas da comunidade local, como também pontuado por José Fialho (2003) em Moçambique e tendo como referência os sistemas de saúde popular daquele país. Assim, esse questionamento acerca da eficácia de um determinado tratamento, como endereçado no presente estudo, por vezes é um elemento externo a essa comunidade e responde a inteligibilidades produzidas por outrem e fora do contexto de referência.

Além disso, é importante compreender que o reconhecimento público da eficácia de determinados procedimentos espirituais realizados na umbanda é responsável pela construção de uma memória coletiva acerca desse equipamento popular de cura. Assim, o terreiro passa a ser validado socialmente como um espaço de cuidado e de conforto que pode fornecer os resultados almejados pela população que acessa esses serviços. Esses resultados, obviamente, não podem ser interpretados apenas a partir de marcadores objetivos que podem atestar os processos de mudanças por meio de métricas específicas e próximas do modelo biomédico, mas, sobretudo, pelo modo como essa comunidade constrói a sua própria inteligibilidade sobre a eficácia, que pode estar também relacionada a processos como o acolhimento, o cuidado perene e mesmo o reconhecimento dos processos de adoecimento experienciados por esses consulentes.

Essa validaçáo passa a ser comunicada e transmitida pela coletividade, de modo que o terreiro passa a ser chancelado como espaço de cura e de resoluçáo de conflitos, sobretudo em termos de processos de saúde e doença, podendo tanto funcionar como um equipamento complementar ao cuidado formal, representado por hospitais e centros de saúde, por exemplo, como também um sistema que opere em oposição a estes espaços formais. Embora a umbanda trabalhe com a noção de complementaridade (Montero, 1994; Silva, Scorsolini-Comin, 2020), náo criando oposiçôes entre tais sistemas de cura e de cuidado, há que se considerar que o meio social pode criar e perpetuar ambos os sentidos, a depender da eficácia não apenas verificada a partir das práticas rituais, mas também do modo como as mesmas são comunicadas e difundidas socialmente.

\section{Solicitação e execução dos pedidos realizados pelas entidades}

Esta categoria engloba o reconhecimento das solicitaçóes realizadas pelas entidades, o valor destinado às mesmas e o significado concedido no momento da execuçáo dos pedidos. A solicitaçáo por parte das entidades e a execução do que foi solicitado compóem um construto que engloba a confiança nas orientaçóes estabelecidas, como também a crença de que cumprir com algo simbólico poderá trazer benefícios para as queixas de saúde e até a cura. A importância desse simbolismo e o significado aplicado nas crenças religiosas, bem como no momento das realizaçóes, podem ser observados nas seguintes falas.

Pediu pra acender vela pro anjo de guarda, banho de rosa branca, banho arruda com guiné com manjericão. Fiz tudo, não deixei de fazer (P1). 
Tô fazendo as coisas que eles falaram pra mim, colocando vela pro guia, agradecendo, falavam pra eu colocar vela pro meu anjo da guarda, pedindo proteção (P2).

Por meio dessas falas, podemos observar que existe um aspecto simbólico intrínseco no momento das realizações dos pedidos. Existe a crença naquela entidade responsável pelas solicitaçóes, a conviç̧ão e a confiança depositada no centro e nos benefícios a serem adquiridos com a execuçáo dos rituais solicitados. A participação do sujeito, bem como a fé depositada, estáo em conformidade com as experiências vividas tanto pelo próprio indivíduo adoecido quanto pelo feiticeiro, utilizando a nomenclatura de LéviStrauss (1975), que dispõe da integração entre conhecimento e a eficácia simbólica. Nesse sentido, não há razão para imposição de dúvidas em relação aos processos de cura espiritual, mas sim confiar e dar credibilidade na missão religiosa de curar (LéviStrauss, 1975).

A questão da confiança pode ser notada na fala a seguir, em que o consulente (P6) relata que realiza as orientações mediante uma crença pré-estabelecida, e que a ausência desta crença pode provocar resultados insatisfatórios. Nesses dizeres podemos reforçar que os consulentes identificam e associam seus resultados com a credulidade depositada no momento de utilizar os objetos materiais orientados, sendo o mais comum deles o emprego das velas, como forma de proteção espiritual.

Além disso, podemos destacar a associação da execuçáo das orientaçóes a uma possível conduta disciplinar. Em outros termos, diz-se que aquele que realiza o que the foi orientado estará cumprindo com seu papel religioso, com a obtençáo de resultados positivos e com a evoluçáo dos processos de cura. Esses aspectos podem ser destacados na fala a seguir, no momento em que o consulente relata que cumprir com o que foi orientado está intimamente ligado a um comportamento disciplinado, e que havendo a combinação de aspectos como as instruçóes e ensinamentos do guia espiritual e o compromisso e responsabilidade do consulente em desenvolver aquilo que se foi instruído, obtém-se um tratamento mais completo.

Leitura do evangelho, banho de descarrego, acender vela pro anjo da guarda, carregar patuá no bolso (com sal e alho). Sempre fiz, sou disciplinado (P3).

Sempre pedem, e eu sempre faço, sigo à risca pra ter um resultado positivo, acender vela pro anjo de guarda, oraçóes em nome da entidade, banhos de descarrego (P13).

Diante disso, podemos enfatizar a questão da relação entre a magia e a sociedade, englobando não somente a crença depositada nesta magia, mas a responsabilidade social perante essas práticas. Esses marcadores acabam por promover uma identidade social que prevalece sobre o indivíduo, construindo suas crenças e compondo sua essência, com elementos materiais e imateriais, de iniciação e confirmação dos rituais. Além disso, sugere-se que o não cumprimento dos rituais de confirmação, ainda que associados ao simbolismo, podem propiciar o enfraquecimento da espiritualidade (Montero, 1994). Outro sentido emergente é o de que a observância rigorosa e disciplinar dessas "prescriçóes" para um desfecho positivo também é compartilhada pelo modelo biomédico, de modo a aproximar essas inteligibilidades e, consequentemente, as noçôes de eficácia produzidas em cada contexto de produção de cuidado. 
Esses elementos relativos a uma espécie de "barganha" com o mundo espiritual foram destacados por Augras (2012) também no contexto religioso dos pedidos endereçados aos santos católicos. Assim, esse marcador não seria exclusivo da umbanda, mas atravessaria uma gama de religióes. Os princípios de troca e de favor sustentam muitas das práticas religiosas em diferentes tradiçóes, o que pode estar relacionado com as assimetrias e desigualdades sociais. Assim, em um contexto socialmente desigual e opressor como o brasileiro, sobretudo em cenários de crise, as comunidades apartadas dos sistemas de produção e não detentoras do capital podem recorrer à religião e às práticas mágicas como forma de conseguir aquilo que desejam, segundo Augras (2012). Para que essa aquisição seja possível, opera-se o princípio da troca e do favor, de modo que se explicita uma relaçáo simbólica entre o consulente e a entidade espiritual, selando uma conexão que se dá a partir do que cada um pode oferecer ou receber nesse processo.

\section{Simbolismos catalizadores da eficácia}

A partir dos relatos, podemos observar que muitas vezes o simbolismo da eficácia vem associado a acontecimentos no momento da execução dos pedidos. Tais simbolismos são identificados e verbalizados pelos consulentes:

As entidades pediam os banhos com arruda, espada de São Jorge e rosa-branca. Nos primeiros banhos, as minhas toalhas ficavam pretas, e o dia que tomei o último banho que foi de rosa-branca a toalha continuou branquinha. Tudo que pede, eu faço (P10).

$\mathrm{Na}$ fala dessa participante, podemos observar que a mesma associou a coloração obtida na toalha com as dádivas recebidas pelas entidades. Elencando a cor preta como sendo correspondente aos maus fluidos retirados no momento dos banhos, e a cor branca estando associada à aquisição da serenidade e da possível cura obtida por meio das graças espirituais, opera-se um sistema simbólico que não é exclusivo dessa consulente, mas que atravessa toda a comunidade, criando uma interpretação que também é coletiva (Macedo, 2015). Esse universo simbólico também está entrelaçado ao potencial produzido pelas instituições, que incita a motivação, definindo-se atitudes e rituais direcionados ao sagrado (Montero, 2014).

Esta dualidade entre convicção e interpretação pode ser identificada nos estudos de Lévi-Strauss (1975) que contemplam a questão dos estados patológicos terem alguma fundamentação, um motivo para que os mesmos aconteçam, bem como um lado voltado para a representatividade, em que o sujeito usa de sua interpretaçáo pessoal para justificar as diferentes circunstâncias desde o adoecimento até o processo de cura por meio da assistência religiosa. No caso do excerto apresentado, destaca-se que a interpretação pode não se alocar exclusivamente no sujeito, representando a sua subjetividade, mas também revelar um processo interpretativo coletivo, em que tais sentidos são validados pela comunidade como sendo representações da eficácia atribuída à intervenção espiritual mediada pelo terreio e pela consulta.

Desse modo, alguns simbolismos são compartilhados socialmente como equivalentes à cura ou como indícios de alguma mudança que pode conduzir à concretização do 
desejo do adepto. Assim, pode-se compreender que a umbanda também possui elementos mágicos que permitem a interpretação de seus rituais, conferindo sentidos para a noção de eficácia que partem de representações, muitas vezes concretas e materiais, que são simbolicamente associadas a determinados estados, como a cura, representando ou equivalendo, em muitos casos, à própria cura. Tais representaçóes são compartilhadas socialmente, permitindo a construção de uma inteligibilidade acerca da eficácia que se sustenta nessa coletividade.

\section{A eficácia do trabalho mediunico mediante o comportamento dos consulentes}

Esta categoria descreve que alguns comportamentos são considerados fatores determinantes para a ênfase e eficácia dessa assistência religiosa, como, por exemplo, as crenças e os pensamentos otimistas depositados e associados aos tratamentos espirituais (Amaral et al., 2016). Nas falas desses consulentes, nota-se que os mesmos enfatizam a questáo do otimismo no momento de execuçáo das orientaçôes, e que estas podem estar intimamente ligadas a formas de proteção contra influências malignas ou maus fluidos.

A partir dessas falas, pode-se exemplificar a validação coletiva acerca da eficácia, assim como trabalhado por Lévi-Strauss (1975). Para que uma determinada prática mágica seja considerada adequada e digna de credibilidade, náo apenas é preciso que se acredite na mesma: é preciso que esse adepto possa também controlar os seus pensamentos, criando uma disponibilidade interna para tal crença. O chamado pensamento positivo referido por $\mathrm{P} 15$ representa que, em conjunto com o poder da prática ritual, o consulente também opera no sentido de promover essa eficácia. $O$ poder do feiticeiro, desse modo, deveria receber o apoio irrestrito do consulente para que, de fato, haja a eficácia. A prática mágica, sem a crença e o apoio do consulente, não teria os mesmos resultados.

Essa noçáo atravessa a maioria dos relatos dos participantes do presente estudo, localizando o consulente como um vértice fundante do processo de cura ou de restabelecimento da saúde. Assim, para a eficácia da magia, nesse contexto, é importante que o consulente náo apenas acredite e valide o tratamento espiritual recebido pelas entidades, como pode-se depreender da leitura de Lévi-Strauss (1975), mas que ele, de modo ativo, possa ser produtor de saúde a partir da construçáo de repertórios de pensamento, de confiança, de motivaçáo e de comportamentos de cuidado que, em conjunto, podem produzir a cura. $\mathrm{O}$ papel ativo desse paciente-cliente-consulente-frequentador nos tratamentos de saúde deve ser fomentado pelas entidades, mas também transmitido pela comunidade como forma de posicioná-la como parte desse cuidar não no sentido apenas de recebimento de uma atenção, mas de efetiva participaçáo nesse processo e, consequentemente, na produçáo de sentidos sobre a eficácia.

Podemos enfatizar que a umbanda considera o indivíduo em uma perspectiva integral, mesclando aspectos físicos, mentais, espirituais e também energéticos. Essas energias, na umbanda, são consideradas importantes por influenciarem estados de espírito e comportamentos. Diante disso, rituais podem ser concretizados para que se contorne ou neutralize as açóes perversas por meio de energias direcionadas aos 
consulentes, aspecto presente não somente na umbanda, mas nas demais religióes de tradição africana. No entanto, estudos apontam que a questáo do mal é algo externo, e que muitas vezes se abate sobre o indivíduo sem que este possa evitá-lo, e que só é concebido quando materializado sob a forma de doença e morte (Montero, 1994), permitindo uma representaçáo corporificada do adoecimento ou de uma determinada desordem (Laplantine, 1986).

A partir das categorias discutidas no presente estudo, pode-se afirmar que, ao longo do tempo, crenças e ritos foram se modificando, sendo transformados com a modernização da sociedade brasileira, assumindo condiçóes significativas e bastante relevantes para a sociedade, interligando-se à produção da saúde e à experiência da doença, buscando-se compreender as interpretaçóes vividas pelo sujeito e o significado dado por ele a estas experiências ritualísticas (Montero, 1994; Langdon, 2014; Marin, Scorsolini-Comin, 2017). Diante das questóes recuperadas na presente investigação, observa-se o aumento do interesse nas temáticas que englobam os aspectos da R/E na busca pela cura, havendo a necessidade de compreender o significado dos comportamentos religiosos e dos aspectos simbólicos como forma de auxílio na superação de adversidades, bem como nos processos de cura para enfermidades (Holt, Clark, Debnam, Roth, 2014).

No que tange especificamente à noçáo de eficácia, foco do presente estudo, há que se recuperar que os consulentes entrevistados a situam a partir de marcadores que consideram as vozes sociais que indicam determinados tratamentos, o modo como o consulente se apresenta diante destas prescriçóes e como a comunidade de referência interpreta as respostas dos sujeitos e seus organismos, possibilitando a emergência de uma inteligibilidade que narra a eficácia de um ponto de vista integrativo e não meramente biomédico, ou seja, que pode ser mensurado de modo objetivo e atendendo a métricas compartilhadas em meios científicos e/ou profissionais.

A umbanda, na perspectiva desses consulentes, permite a emergência de uma noção de eficácia complexa, multideterminada e que não propóe uma análise objetiva de evidências, mas justamente a convivência de diferentes perspectivas que permitem ao sujeito e à sua coletividade narrarem acerca do que é a cura, do que é o acolhimento e de como a umbanda pode ser significativa nesse processo de atenção à saúde. Para além de uma eficácia simbólica que possa ser, pretensamente, explicada em termos de vértices interligados e relativamente fixos, há que se problematizar constantemente a construção de inteligibilidades distintas que narrem a eficácia a partir de diferentes endereçamentos. Ao priorizar os discursos dos consulentes visamos à produção de uma noção de eficácia em campo que, pelos resultados aqui discutidos, revela a sua complexidade, em consonância com leituras mais contemporâneas que também visam a revisitar uma noção mais tradicional de eficácia simbólica (Fialho, 2003; Tavares, Bassi, 2013).

\section{Consideraçóes finais}

Como aspecto importante deste estudo, podemos destacar que a umbanda tornou-se um equipamento popular importante nos atendimentos às questóes de saúde, principalmente por contemplar os sujeitos de forma holística, em sua totalidade. Obviamente que 
a busca por tal equipamento pode estar mais localizada em determinadas comunidades e camadas sociais, o que náo pode ser interpretado de modo automático como uma demanda existente em localidades nas quais há menor oferta de uma estrutura formal de saúde, o que poderia associar a R/E a uma condiçáo alternativa ou complementar, o que tem sido combatido pela literatura da área, que reforça a importância deste vértice na estruturação do conceito de saúde. Assim, a R/E não seria algo complementar ou tangencial, mas central.

Destaca-se que diversos consulentes, na busca incessante por boas condiçóes de saúde, adentram ao universo religioso e espiritual como forma de restabelecer algo que se considera fragilizado, e na tentativa de se obter conforto e alívio nas particularidades do adoecimento, almejando-se benefícios promovidos pelas consultas mediúnicas (Silva, Scorsolini-Comin, 2020). Essas consultas mostraram-se integradas a outros sistemas nos quais os seus adeptos transitam, inclusive permitindo a frequência a outros equipamentos religiosos paralelamente, em um sentido de porosidade recuperado no estudo de Augras (2012). Desse modo, o tratamento na umbanda náo assume uma posição de exclusividade e de negação de outras práticas que podem se dar concomitantemente, quer seja em um campo formal de cuidado ou recorrendo a outros equipamentos religiosos/espirituais. Obviamente que esses atravessamentos demandam a constante revisitação do conceito de eficácia em uma perspectiva complexa e crítica.

Os resultados obtidos por meio do tratamento espiritual demonstram que objetos materiais e imateriais fazem parte da justificativa para a continuidade do processo de cura orientado pelas entidades. O cumprimento e a execuçáo das orientaçóes realizadas pelos guias espirituais estáo intimamente relacionados à convicçáo depositada no equipamento e no guia espiritual, bem como no médium de incorporaçáo. De outra maneira, a postura de incredulidade quanto a essas técnicas e esses elementos pode estar relacionada a uma percepçáo de não ter obtido os resultados almejados a partir do envolvimento nesses procedimentos e nesse universo.

O estudo apresentou que os consulentes conferem poder e confiabilidade aos trabalhos concebidos e que atribuem aos rituais religiosos o papel de responsabilidade social e identidade religiosa, e por meio destes os consulentes trabalham a questáo do simbolismo e da crença aplicados no momento de execuçáo das orientaçóes, pontuando-se que os benefícios do tratamento espiritual só são possíveis mediante a integração da crença, da fé e do compromisso religioso. Os consulentes consideram que o cuidado em saúde no terreiro de umbanda auxilia na expansão do enfrentamento dos processos de saúde e doença. Por meio das práticas religiosas pode-se adquirir proteção espiritual, tornar-se mais confiante e fortalecer a construçáo de resultados benéficos à saúde promovidos pela umbanda. Todos esses elementos costuram um sentido de eficácia que náo apenas é produzido dentro do terreiro, como validado por esse contexto, performando práticas e condutas.

Pode-se concluir que a umbanda, ao ser situada como equipamento popular de saúde, permite a emergência de uma noção de eficácia que ultrapassa o modelo biomédico, em um modelo de integralidade e de humanização. Nesse novo paradigma, a eficácia deixa de ser uma evidência que comprova a melhora, a cura ou a evolução e passa a ser indício que destaca as expectativas produzidas pela coletividade e que legitimam um 
determinado espaço como sendo de cuidado e de acolhimento e determinada prática mágica como sendo um procedimento para o restabelecimento da saúde.

Assim, não podemos nos comprometer com uma noção única de eficácia, produzida a partir de marcadores que desconsideram o sujeito em interaçáo, em seu universo simbólico, reduzindo-o ao funcionamento ótimo de órgãos, sistemas e estruturas biomédicas. A umbanda, difundindo uma visão de ser humano complexo e integrado, permite que o cuidado - e, consequentemente, a eficácia - sejam refletidos tendo como norteadores um universo experiencial que situa o sujeito consulente, as práticas místicas, os tratamentos, as práticas de promoção de saúde, médiuns e entidades dentro de um mesmo sistema responsável pela oferta de uma atençáo humanizada.

Uma limitação da presente investigação foi não ter acompanhado os consulentes ao longo do processo representado pelas consultas, pelos retornos e pela avaliação final do tratamento. Ao acessar esse sujeito em um determinado ponto do tratamento, sobretudo em seu início, pode-se recuperar de modo mais expressivo uma motivação construída a partir das recomendaçóes da comunidade de referência ou de pessoas próximas, em detrimento de uma justificativa individual para a busca dessa forma de cuidado e de tratamento. Estudos vindouros podem se estruturar no sentido de não apenas acompanhar os itinerários desses adeptos ao longo dos atendimentos, como também comparar os sentidos sobre eficácia construídos antes, durante e após o tratamento, verificando possíveis mudanças nestes sentidos em função da interpretação dos resultados obtidos a cada consulta.

\section{Referências}

ABDALA, Gina Andrade; KIMURA. Miako; DUARTE, Yeda Aparecida de Oliveira; LEBRÃO, Maria Lúcia; SANTOS, Bernardo dos. Religiosidade e qualidade de vida relacionada à saúde do idoso. Revista de Saúde Pública, v, 49, n. 55, pp. 1-9, 2015.

AMARAL, Juliana Bezerra; MENEZES, Maria do Rosário; SILVA, Valdenir Almeida da; OLIVEIRA, Cíntia Maria Souza de. A religiosidade e a espiritualidade como referências para o enfrentamento da violência doméstica contra idosos. Revista de Enfermagem UERJ, Rio de Janeiro, v. 24, n. 2, p. e7126, 2016.

AUGRAS, Monique. A segunda-feira é das almas. Rio de Janeiro: Pallas, 2012.

BRAUN, Virginia; CLARKE, Victoria. Reflecting on reflexive thematic analysis. Qualitative Research in Sport, Exercise and Health, v. 11, n. 4, pp. 589-597, 2019.

CONCONE, Maria Helena Villas Bôas. A umbanda, as notícias e os números. Revista Pós Ciências Sociais, v. 11, n. 21, pp. 59-84, 2014.

CUNHA, Vivian Fukumasu; SCORSOLINI-COMIN, Fabio. Best professional practices when approaching religiosity/spirituality in psychotherapy in Brazil. Counselling and Psychotherapy Research, capr.12241, 2019.

DELMONTE, Romara; FARIAS, Miguel. A mente brasileira em estado de possessão: contribuição de um estudo de caso para a psicologia da religião e saúde mental no Brasil. Revista Pistis e Práxis: Teologia e Pastoral, v. 9, n. 1, pp. 243-256, 2017. 
FIALHO, José. A eficácia simbólica nos sistemas tradicionais de saúde. Cadernos de Estudos Africanos, v. 4, pp. 121-133, 2003.

HOLT, Chery L.; CLARK, Eddie M.; DEBNEM, Katrina J.; ROTH, David L. Religion and Health in African Americans: The Role of Religious Coping. American Journal of Health Behavior, v. 38, n. 2, pp. 190-199, 2014.

LANGDON, Esther Jean. Os diálogos da antropologia com a saúde: contribuiçóes para as políticas públicas. Ciência \& Saúde Coletiva, v. 19, n. 4, pp. 1019-1029, 2014.

LAPLANTINE, François. Antropologia da doença. Sáo Paulo: Martins Fontes, 1986.

LEAL DE BARROS, Mariana; BAIRRÃO, José Francisco Miguel Henriques. Etnopsicanálise: embasamento crítico sobre teoria e prática terapêutica. Revista da SPAGESP, Ribeirão Preto, v. 11, n. 1, pp. 45-54, 2010.

LÉVI-STRAUSS, Claude. Antropologia estrutural. Rio de Janeiro: Tempo Brasileiro, 1975.

LUTZ, Catherine. Ethnopsychology compared to what? Explaining behavior and consciousness among the Ifaluk. In: WHITE, G. M.; KIRKPATRICK, J. (Eds.). Person, self and experience: exploring Pacific Ethnopsychologies. University of California Press, 1985, pp. 35-79.

MACEDO, Alice Costa. Encruzilhadas da interpetação na umbanda. Tese (Doutorado em Psicologia) - Faculdade de Filosofia, Ciências e Letras de Ribeirão Preto, Universidade de São Paulo, Ribeirão Preto, SP. 2015. Disponível em: <https://www. teses.usp.br/teses/disponiveis/59/59137/tde-30032016-144127/pt-br.php>. Acesso em: 30 jun. 2020.

MALUF, Sônia Widner. Mitos coletivos e narrativas pessoais: cura ritual, trabalho terapêutico e emergência do sujeito nas culturas da "Nova Era". Mana, v. 11, n. 2, pp. 499-528, 2005.

MARIN, Raquel Cornélio; SCORSOLINI-COMIN, Fabio. Desfazendo o "mauolhado": magia, saúde e desenvolvimento no ofício das benzedeiras. Psicologia: Ciência e Profissão, Brasília, v. 37, n. 2, pp. 446-460, 2017.

MONTERO, Paula. A teoria do simbólico de Durkheim e Lévi Strauss: desdobramentos contemporâneos no estudo das religiōes. Novos Estudos, v. 98, pp. 125-142, 2014.

MONTERO, Paula. Magia, racionalidade e sujeitos políticos. Revista Brasileira de Ciências Sociais, v. 9, n. 26, pp. 72-90, 1994.

NEGRÃO, Lísias Nogueira. Umbanda: entre a cruz e a encruzilhada. Tempo Social Revista de Sociologia da Universidade de São Paulo, v. 5, n. 1-2, pp. 113-122, 1993.

RENSHAW, John. A eficácia simbólica revisitada: cantos de cura ayoreo. Revista de Antropologia, São Paulo, v. 49, n. 1, pp. 393-427, 2006. 
SCORSOLINI-COMIN, Fabio. Atenção psicológica e umbanda: Experiência de cuidado e acolhimento em saúde mental. Estudos e Pesquisas em Psicologia, v. 14, n. 3, pp. 773-794, 2014.

SILVA, Luciana Macedo Ferreira; SCORSOLINI-COMIN, Fabio. Na sala de espera do terreiro: uma investigação com adeptos da umbanda com queixas de adoecimento. Saúde e Sociedade, São Paulo, v. 29, n. 1, e190378, 2020.

TAVARES, Fátima; BASSI, Francesca. Efeitos, símbolos e crenças: consideraçóes para um começo de conversa. In: Para além da eficácia simbólica: estudo em ritual, religiáo e saúde. Salvador: EDUFBA, 2012, pp. 17-28.

ZERBETTO, Sonia Regina; GONÇALVES, Angélica Martins de Souza; SANTILE, Nátaly; GALERA, Sueli Aparecida Frari; ACORINTE, Ana Carolina; GIOVANNETTI, Gisele. Religiosidade e espiritualidade: mecanismos de influência positiva sobre a vida e tratamento do alcoolista. Escola Anna Nery, v. 21, n. 1, e20170005, 2017.

Recebido: $01 / 07 / 2020$

Aprovado: 30/11/2020

Editor: Antonio Genivaldo C. de Oliveira 